\title{
Efficacy of the spray-drying treatment to inactivate the bovine leukemia virus in bovine colostrum
}

\author{
Marina Lomónaco, ${ }^{1 *} \dagger$ ๑ Mariana Sowul,,${ }^{1,2 *}$ Gerónimo Gutiérrez, ${ }^{1}$ Dario Malacari, ${ }^{1}$ Irene Álvarez, ${ }^{1,3}$ (1) \\ Natalia Gabriela Porta, ${ }^{1,3}$ Osvaldo Zabal, ${ }^{1}$ and Karina Trono ${ }^{1,3}$ \\ ${ }^{1}$ Instituto de Virología, Centro de Investigaciones en Ciencias Veterinarias y Agronómicas, Instituto Nacional de Tecnología Agropecuaria (INTA), \\ Nicolas Repetto y de los Reseros s/n (B1686 LQF), Hurlingham, Buenos Aires, Argentina \\ ${ }^{2}$ Servicio Nacional de Sanidad y Calidad Agroalimentaria, Paseo Colon 367 (ACD1063), Buenos Aires, Argentina \\ ${ }^{3}$ Consejo Nacional de Investigaciones Científicas y Técnicas, CONICET, Godoy Cruz 2290 (C1425FQB), CABA, Argentina
}

\section{ABSTRACT}

Previous studies have shown the presence of bovine leukemia virus (BLV) in colostrum and milk of naturally infected cows. The relationship between virus or provirus and specific antibodies in these secretions is particular to each infected cow and will probably determine whether the consumption of colostrum or milk from these naturally infected dams provides an infective or a protective effect in recipient calves. Our recent findings suggest that this issue is a key point in BLV transmission in very young calves. Based on this, the aim of the present study was to determine the effect of the spray-drying treatment of colostrum on BLV infectivity. The treatment was done on scale-down conditions, using fresh colostrum from BLV-negative cows spiked with infective BLV. Residual infectivity was tested in susceptible lambs. Lambs inoculated with colostrum spiked with BLV-infected cells or cell-free BLV showed evidence of infection $60 \mathrm{~d}$ after inoculation, whereas none of the lambs inoculated with spraydried colostrum showed evidence of infection $60 \mathrm{~d}$ after inoculation. These results provide direct evidence that the experimental spray-drying process used in this study was effective in inactivating infectious BLV in colostrum. These findings suggest that the risk for BLV transmission could be reduced if milk and colostrum were treated by spray-drying prior to consumption in dairy facilities. The effect of spray-drying on the functional properties and stability of the antibodies present in colostrum under long-term storage should be further investigated.

Key words: bovine leukemia virus, colostrum, spraydrying

Received November 20, 2019

Accepted February 23, 2020.

*These authors contributed equally to this work.

†Corresponding author: lomonaco.marina@inta.gob.ar

\section{INTRODUCTION}

Bovine leukemia virus (BLV) is widely distributed in the Americas, with high individual prevalence and clinical disease appearance in dairy herds under intensive management (https://www.oie.int/wahis_2/ public/wahid.php/Diseaseinformation/statuslist). The endemicity of bovine leukemia in Argentina has increased from the first report in 1973, reaching a herd prevalence of more than $80 \%$ in the most productive areas of the country (Trono et al., 2001). A recent study has shown that around $10 \%$ of newborn calves are infected, with a high incidence during the first $2 \mathrm{yr}$ of age, reaching around $50 \%$ prevalence before the first calving (Gutiérrez et al., 2011; Merlini et al., 2016). According to internal farm reports, up to $5 \%$ of cows die because of BLV-associated lymphosarcoma, which is associated with a loss of profits of more than $\$ 5,000$ per animal (Castellano and Goizueta, 2014). Although some studies have shown that the antibodies present in milk and colostrum protect against neonatal infection (Van Der Maaten et al., 1981), others have detected both virus and provirus in these secretions and confirmed their infectivity by experimental inoculation and oral consumption (Romero et al., 1983). Thus, the ability of colostrum and milk to either infect or protect from BLV-infected dams remains controversial. Considering a potential failure in the transfer of passive immunity, common management at dairy facilities is artificial supply of fresh or frozen colostrum to newborn calves from a bank to complement the natural intake from its mother during the first day of life (Stott et al., 1979; Reschke et al., 2017).

Despite the importance of colostrum consumption, this secretion also represents one of the first potential exposures of calves to infectious agents other than BLV (Waldner and Rosengren, 2009; Lorenz et al., 2011). Some effective practices to inactivate these pathogens, including BLV, include freezing and pasteurization (Baumgartener et al., 1976; Rubino and Donham, 1984; 
Godden et al., 2006). However, these practices also reduce immunoglobulin concentrations (Godden et al., 2003). Thus, the aim of this study was to evaluate the effectiveness of spray-drying treatment of colostrum to inactivate BLV infectivity under scale-down conditions, as an alternative to eliminating a potential source of BLV transmission and to provide good passive immunity.

\section{MATERIALS AND METHODS}

\section{Experimental Contamination of the Colostrum Pool with BLV}

The FLK-BLV cell line is persistently infected with BLV and constantly secretes viral particles to the supernatant without cytopathogenic effect (Van Der Maaten and Miller, 1976). Both FLK-BLV supernatant and FLK viable cells were used as inocula for experimental contamination of colostrum, as described below. The FLK-BLV cell line was kindly provided by Dr. Luc Willems (University of Liège, Belgium).

The FLK cells were cultured in RPMI 1640 medium (Corning Inc., Corning, NY) with the addition of sodium pyruvate $(1 \%)$ and HEPES $(2.5 \%)$ and supplemented with $10 \%$ irradiated fetal bovine serum (Internegocios SA, Buenos Aires, Argentina). Cultures were maintained at $37^{\circ} \mathrm{C}$ with $5 \% \mathrm{CO}_{2}$ until formation of a confluent monolayer, when the medium was replaced with maintenance medium and cultured for $48 \mathrm{~h}$. The supernatant containing cell-free BLV was harvested, clarified by centrifugation at $4,500 \times g$ at $4^{\circ} \mathrm{C}$ for 15 min, and stored at $-65 \pm 10^{\circ} \mathrm{C}$ until use. Cells in the monolayer were removed using trypsin, washed 3 times with PBS, resuspended, and counted by the trypan blue exclusion method.

Two spray-drying processes were independently performed using $10 \mathrm{~L}$ of colostrum as the starting material for each process (pool 1 and pool 2, Figure 1). This colostrum was prepared as a pool of individual colostrum collections from uninfected cows from a BLV-free dairy farm. All individual collections, as well as the pools, were confirmed negative for BLV-specific antibodies and provirus in our laboratory and kept frozen at $-20^{\circ} \mathrm{C}$ until the moment of use. These $10-\mathrm{L}$ fractions were independently contaminated with $10^{9}$ viable BLVinfected cells from the FLK-BLV cell line (pool 1) or with $600 \mathrm{~mL}$ of fresh supernatant of FLK-BLV cells containing cell-free BLV virus (pool 2). A third 10-L fraction of colostrum, made with individual colostrum collected from BLV-infected cows with detectable antibodies against BLV as well as against bovine viral diarrhea virus (BVDV) and bovine rotavirus (BRV), was subjected to the spray-drying process (pool 3) to confirm the efficacy of the process to preserve immunoglobulins. A $150-\mathrm{mL}$ fraction of negative colostrum contaminated with BLV-infected cells $\left(1.5 \times 10^{6}\right)$ and another $150-\mathrm{mL}$ fraction contaminated with cellfree BLV (9 mL of fresh FLK supernatant) were left untreated to verify the infectivity or interference of the material without treatment. These fractions were prepared immediately before performing the infectivity test in sheep (Figure 1).

The amount used for the experimental contamination of both FLK-BLV cells and cell-free BLV was more than 10 times that necessary to induce an experimental infection in lambs or calves, according to data previously obtained in our laboratory (Porta et al., 2019).

\section{Spray-Drying of the Colostrum Pools}

The spray-drying or atomization treatment of pools 1,2 , and 3 (Figure 1) was carried out in a Galaxie 1612 spray dryer, following the recommendations of personnel of Galaxie Argentina (Buenos Aires, Argentina). The colostrum load was performed at $180^{\circ} \mathrm{C}$ and the spray-drying process was carried out at $80^{\circ} \mathrm{C}$ to preserve the antibodies. A flow diagram of the process, together with a brief description, is shown in Figure 2. Once the drying was performed, the colostrum powder was preserved at room temperature.

\section{Infectivity Bioassay in Sheep}

The procedures in the Manual of the Institutional Committee for Care and Use of Experimental Animals of the National Institute of Agricultural Technology of Argentina (CICUAE-INTA) were used for the handling of animals and the extraction and handling of samples. Eight BLV-free lambs, 3 to 6 mo old, were used. Lambs were kept together in a natural grazing system until the end of the trial, after which they were euthanized.

The spray-dried colostrum powder (pools 1 and 2) was resuspended in its original volume with sterile distilled water. The volume of reconstitution was adjusted by refractometry, taking as reference the concentration of total solids in the colostrum before drying. Two susceptible BLV-free lambs were inoculated for each sample under study. The volume of inoculation was 50 $\mathrm{mL}$ per lamb, which was applied subcutaneously at 4 different sites. This model of infectivity was previously set up in our laboratory (Porta et al., 2019) and is commonly used for the analysis of BLV infectivity in clinical samples (Kanno et al., 2014). The samples without spray-drying treatment were inoculated without any previous manipulation (Figure 1).

The infection was monitored by ELISA and nested PCR. Blood samples were taken into heparinized col- 
lection tubes by jugular venipuncture on the day of the experimental infection ( $0 \mathrm{~d}$ post-infection), and at 30 and $60 \mathrm{~d}$ post-infection. Plasma and buffy coat were obtained by centrifugation at $1,500 \times g$ at $4^{\circ} \mathrm{C}$ for 15 min and stored at $-20^{\circ} \mathrm{C}$ until analyzed.

\section{DNA Purification}

Total genomic DNA was extracted from colostrum and lamb whole blood, using the High Pure PCR Template Preparation Kit (Roche Life Science, Penzberg, Germany) following the manufacturer's instructions.

\section{Detection of BLV Provirus and BLV Antibodies}

The BLV provirus was detected by nested-PCR specific for the tax gene according to a previously reported method (Gutiérrez et al., 2011). The detection limit of this assay was $1 \mathrm{BLV}$-infected cell/10,000 uninfected cells.

Antibodies against the whole viral particle were detected using an indirect ELISA developed and validated in our laboratory (Trono et al., 2001). Samples were assayed in duplicate in 2-fold dilutions; results were expressed as percentage reactivity and determined by
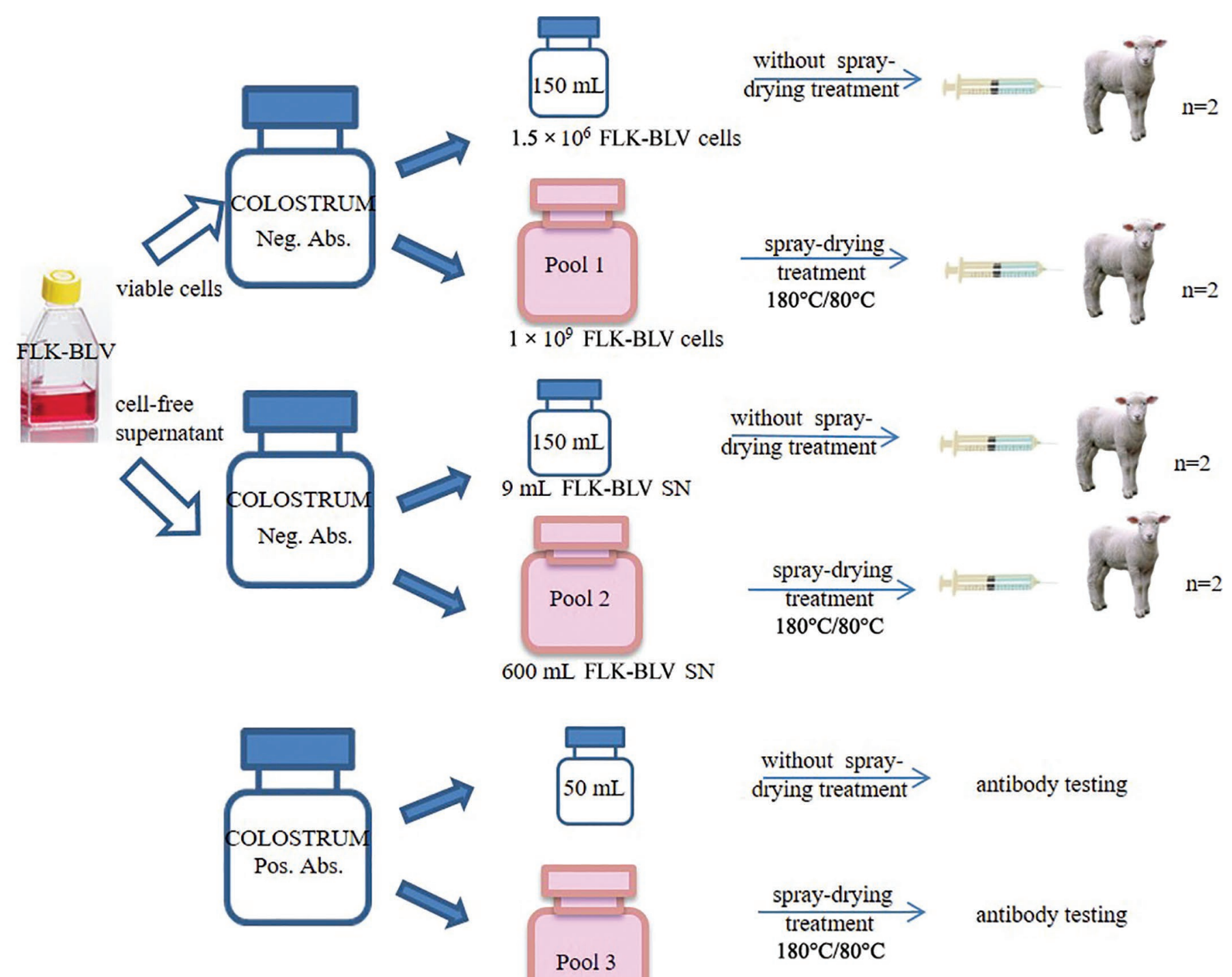

$\underset{\text { drying treatment }}{\stackrel{\text { without spray- }}{>}}$ antibody testing

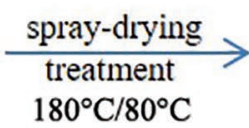

antibody testing

Figure 1. Experimental contamination of colostrum with bovine leukemia virus (BLV) and spray-drying treatment. Neg. Abs. $=$ negative antibodies; Pos. Abs. = positive antibodies. FLK-BLV = cells persistently infected with BLV; SN = supernatant. 


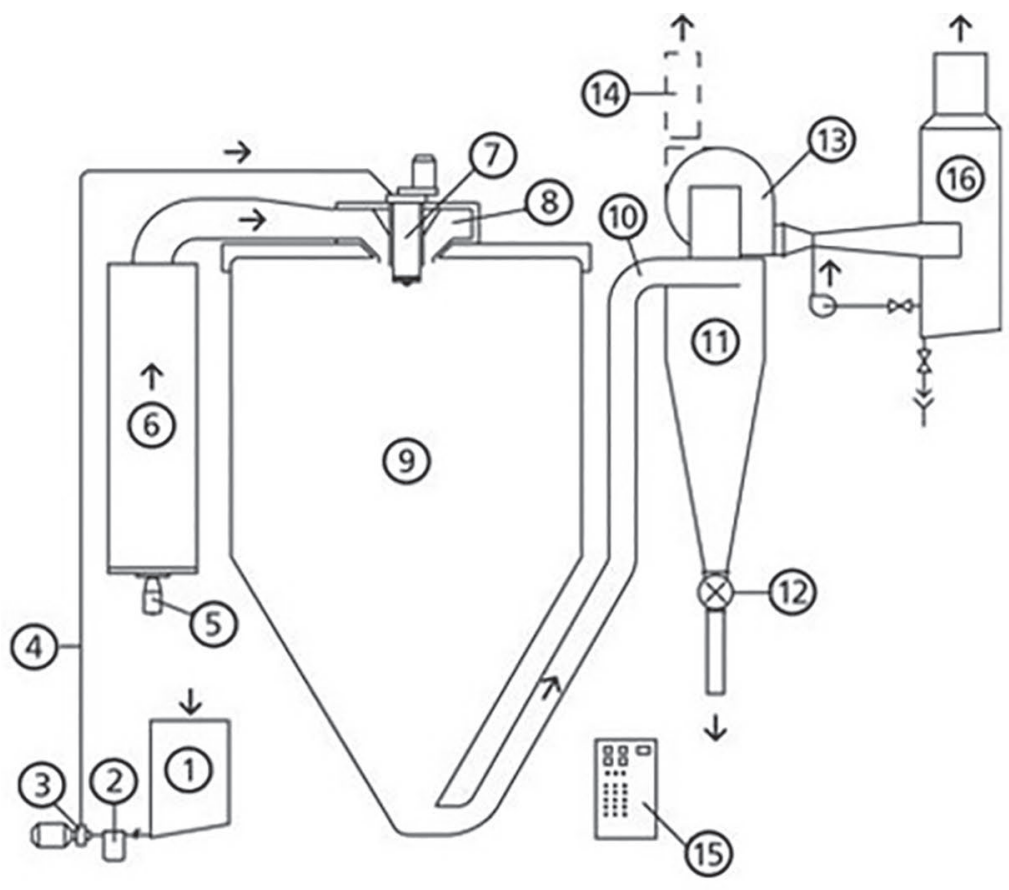

Spray Dryer Components

1) Feeding Tank.

2) Product Filter.

3) Dosing pump.

4) Sets of Pipes, Valves and

Accessories.

5) Complete burner.

6) Hot Gas Generator Direct.

7) Full atomizer.

8) Hot Air Disperser.

9)Drying Chamber with Door and

Peephole.

10) Interconnection Ducts.

11) Product Output Cyclone.

12) Rotary Valve.

13) Aspiration Fan.

14) Fireplace.

15) Control and Command Board.

16) Effluent Gas Washer Components

Figure 2. Flow diagram of a spray-drying process (www.galaxie.com.ar). Briefly, the process begins with the loading of colostrum in the feed tank (1), from where it is driven through a pump (3) to the atomizer (7), previously passing through a filter. In the atomizer, it receives a uniform stream of hot air that pulverizes it. Drying (9) occurs almost instantaneously due to the size of the drop. Finally, the residual air is separated from the powder (11) and the process ends with a dry colostrum powder.

absorbance ratio obtained by the sample with respect to the weak positive control and the negative plaque control. All sera with reactivity $\geq 25 \%$ were declared positive, as defined during previous validation (Gutiérrez et al., 2009).

\section{Detection of BVDV and BRV Antibodies}

Antibodies against BVDV were detected and measured by seroneutralization assay. Samples were assayed in 4-fold dilutions and neutralization titers were assigned according to the positive status of 4 replicates for each dilution (Pecora et al., 2014).

Antibodies against BRV were detected by an indirect ELISA, as previously reported (Fernandez et al., 1996). Samples were run in duplicate in 4-fold dilutions.

\section{RESULTS}

The spray-dried colostrum contaminated with BLVinfected cells and cell-free virus was not infectious for lambs previously stated as BLV-negative, which showed no specific circulating antibodies or provirus, demonstrating the ability of the process to inactivate the virus when more than 10 times the amount of infective virus or cells was used. In contrast, the non-dried colostrum contaminated with both types of inoculum was shown to be infective, showing no nonspecific inactivation of virus by the BLV antibody-free colostrum matrix (Figure 3 ).

Antibodies against BLV and BRV in pool 3 spraydried colostrum were reduced by only one dilution when assayed by ELISA after reconstitution. In the case of BVDV, the neutralization titer changed from 3 to 2.5 , as a consequence of the reduction from 4 to 1 neutralized replicates at the same sample dilution (512; Table 1).

\section{DISCUSSION}

Spray-drying is widely used in many applications of the food and pharmaceutical industries (Masters, 1991) and is an extensively used method for drying protein and improving the stability of antibodies (Ramezani et al., 2017). This process has demonstrated to maintain the quality of live-virus vaccines during storage ( $\mathrm{Li}$ et al., 2015; Kanojia et al., 2017), which is important because the need to maintain the cold chain for these vaccines is challenging. A distinct advantage of this system is the preservation of the functionality of components 


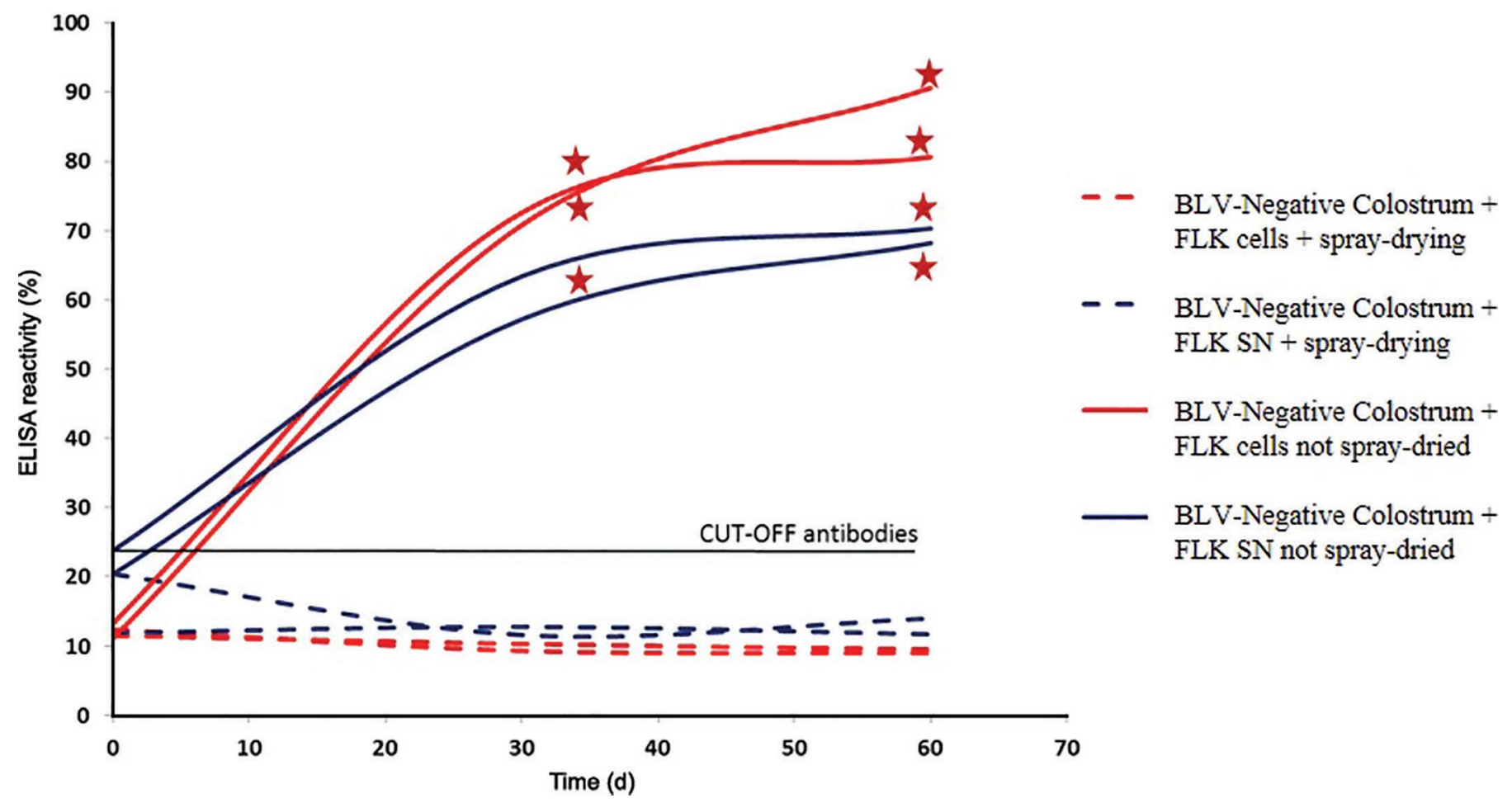

Figure 3. Serology of lambs inoculated with colostrum samples with (dashed line) and without (solid line) spray-drying treatment. Stars indicate a positive result by PCR. BLV = bovine leukemia virus; FLK-BLV = cells persistently infected with BLV; SN = supernatant.

of the biological matrix, particularly immunoglobulins (Niewold et al., 2007; Gikanga et al., 2015; Faghihi et al., 2017), which is of vital importance in products containing antibodies that must be preserved, such as serum, plasma, milk, and colostrum.

In dairy facilities, natural colostrum should be substituted or supplemented using a product that not only provides functional immunoglobulins but also ensures safety in terms of biological contaminants such as BLV. During the neonatal period, calves are at particular risk of becoming infected with BLV, especially on dairy farms where calves are provided with natural or artificial intake of colostrum and raw milk (Ruiz et al., 2018). In Argentina, dairy farms use a colostrum bank containing colostrum from individual cows for supplementation or substitution of natural colostrum; the banked colostrum is preserved in domestic freezers until the moment of use. The state of the cow regarding BLV is not checked before her colostrum is banked and although the colostrum is sometimes heat-treated at $60^{\circ} \mathrm{C}$ before use to ensure inactivation of pathogens, this is not the general procedure. Moreover, heat treatment takes time, reduces the functionality of the immunoglobulins, and may lead to coagulation of the colostrum. In this context, the use of colostrum powder obtained with the spray-drying process is a feasible alternative. The handling of individual secretions for preservation and treatment could be avoided and the procedure could be reduced to rehydrating the powder and using it immediately after calf delivery. In fact, this technology is used in the manufacture of commercial colostrum substitutes that are currently consumed by

Table 1. Titration of antibodies in colostrum with antibodies (pool 3) before (pre) and after (post) the spray-drying process ${ }^{1}$

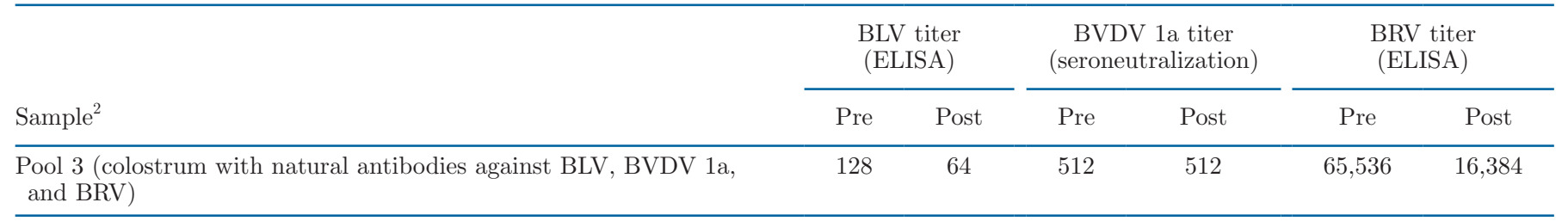

\footnotetext{
${ }^{1}$ Results are expressed as dilutions of the sample under study with a 2-fold dilution (BLV titer) or 4-fold dilution (BVDV 1a and BRV titers).
} ${ }^{2} \mathrm{BLV}=$ bovine leukemia virus; BVDV $1 \mathrm{a}=$ bovine diarrhea virus serotype $1 \mathrm{a}$; BRV = bovine rotavirus. 
cattle and other livestock in several countries. In this context, the presence of BLV-specific antibodies was reported in breeding calves in the United Kingdom, where infection with BLV has been eradicated, due to the use of a colostrum substitute from the United States (Choudhury et al., 2013, 2015), showing the preservation of antibodies in the colostrum powder.

The inactivation of viral infectivity by the spraydrying treatment has been demonstrated (Pujols and Segalés, 2014), although not specifically for BLV or its presence in colostrum. The assays carried out in this study demonstrate that treatment of colostrum by spray-drying is effective for inactivation of cell-associated or cell-free BLV without eliminating specific antibodies against BLV, BVDV, and BRV (Table 1). The antibodies measured after treatment varied in only one dilution from the untreated samples in the case of BLV and BRV, and in the number of replicates within the same dilution in the case of BVDV. This could be an effect of the random variation of the serological assays or a reproducible effect of the treatment, and should be further investigated, together with the functional ability of colostrum powder to protect against BLV challenge, as has been demonstrated for BRV (Vega et al., 2015). The spray-drying treatment is reported to protect the function of immunoglobulins from different sources, particularly from colostrum (Chelack et al., 1993). Considering a potential protective effect of the antibodies in recipient calves, the ultimate purpose would be to adjust the concentration of antibodies to be provided to the calves. In addition to the functionality of antibodies, stabilization should be also studied. Together, these findings provide preliminary evidence for a potential strategy to provide calves with passive immunity in the absence of infectivity.

In Argentina, milk substitute from fluid cow milk and dietary supplements based on egg powder containing specific antibodies against neonatal diarrhea are produced by spray-drying. Although colostrum powder is not produced in our country, we have the capacity to manufacture this type of product, on both small and large scales. Our findings suggest that the risk for BLV transmission could be reduced if colostrum is treated by spray-drying before its consumption in dairy facilities.

\section{ACKNOWLEDGMENTS}

We thank Agustín Vilor (private veterinarian, University of Buenos Aires, Argentina) for the technical assistance with animals. This work was financially supported by project INTA PNSA-1115054 and external funds from specialized technical services of the Virology Institute (INTA) administered by Fundación Argentina
(Buenos Aires). The authors declare no conflicts of interest with respect to the research, authorship, and publication of the article.

\section{REFERENCES}

Baumgartener, L., C. Olson, and M. Onuma. 1976. Effect of pasteurization and heat treatment on bovine leukemia virus. J. Am. Vet. Med. Assoc. 169:1189-1191.

Castellano, A., and M. Goizueta. 2014. Valor Agregado Institucional: Captacion de valor economico Ide innovaciones tecnológicas. IV Congreso Regional de Economía Agraria y XLV Reunión Anual de la Asociación Argentina de Economía Agraria, Octubre 2014. Buenos Aires, Argentina.

Chelack, B. J., P. S. Morley, and D. M. Haines. 1993. Evaluation of methods for dehydration of bovine colostrum for total replacement of normal colostrum in calves. Can. Vet. J. 34:407-412.

Choudhury, B., C. Finnegan, J. P. Frossard, C. Venables, and F. Steinbach. 2013. Colostrum replacer and bovine leukemia virus seropositivity in calves. Emerg. Infect. Dis. 19:1027-1028. https://doi .org/10.3201/eid1906.121523.

Choudhury, B., C. Finnegan, A. Phillips, M. Horigan, T. Pollard, and F. Steinbach. 2015. Detection of bovine leukaemia virus antibodies and proviral DNA in colostrum replacers. Transbound. Emerg. Dis. 62:e60-e61. https://doi.org/10.1111/tbed.12182.

Faghihi, H., A. R. Najafabadi, and A. Vatanara. 2017. Optimization and characterization of spray-dried IgG formulations: A design of experiment approach. Daru 25:22. https://doi.org/10.1186/s40199 -017-0187-8.

Fernandez, F. M., M. E. Conner, A. V. Parwani, D. Todhunter, K. L. Smith, S. E. Crawford, M. K. Estes, and L. J. Saif. 1996. Isotype-specific antibody responses to rotavirus and virus proteins in cows inoculated with subunit vaccines composed of recombinant SA11 rotavirus core-like particles (CLP) or virus-like particles (VLP). Vaccine 14:1303-1312. https://doi.org/10.1016/S0264 $-410 \mathrm{X}(96) 00065-5$.

Gikanga, B., Y. Chen, O. B. Stauch, and Y.-F. Maa. 2015. Mixing monoclonal antibody formulations using bottom-mounted mixers: Impact of mechanism and design on drug product quality. PDA J. Pharm. Sci. Technol. 69:284-296. https://doi.org/10.5731/pdajpst 2015.01031

Godden, S., S. McMartin, J. Feirtag, J. Stabel, R. Bey, S. Goyal, L. Metzger, J. Fetrow, S. Wells, and H. Chester-Jones. 2006. Heattreatment of bovine colostrum. II: Effects of heating duration on pathogen viability and immunoglobulin G. J. Dairy Sci. 89:34763483. https://doi.org/10.3168/jds.S0022-0302(06)72386-4.

Godden, S. M., S. Smith, J. M. Feirtag, L. R. Green, S. J. Wells, and J. P. Fetrow. 2003. Effect of on-farm commercial batch pasteurization of colostrum on colostrum and serum immunoglobulin concentrations in dairy calves. J. Dairy Sci. 86:1503-1512. https://doi.org/ 10.3168/jds.S0022-0302(03)73736-9.

Gutiérrez, G., I. Alvarez, N. Fondevila, R. Politzki, M. Lomónaco, S. Rodríguez, M. J. Dus Santos, and K. Trono. 2009. Detection of bovine leukemia virus specific antibodies using recombinant p24ELISA. Vet. Microbiol. 137:224-234. https://doi.org/10.1016/j .vetmic.2009.01.022.

Gutiérrez, G., I. Alvarez, R. Politzki, M. Lomónaco, M. J. Dus Santos, F. Rondelli, N. Fondevila, and K. Trono. 2011. Natural progression of Bovine Leukemia Virus infection in Argentinean dairy cattle. Vet. Microbiol. 151:255-263. https://doi.org/10.1016/j.vetmic .2011.03.035.

Kanno, T., R. Ishihara, S. Hatama, Y. Oue, H. Edamatsu, Y. Konno, S. Tachibana, and K. Murakami. 2014. Effect of freezing treatment on colostrum to prevent the transmission of bovine leukemia virus. J. Vet. Med. Sci. 76:255-257. https://doi.org/10.1292/jvms $.13-0253$.

Kanojia, G., R. Ten Have, P. C. Soema, H. Frijlink, J.-P. Amorij, and G. Kersten. 2017. Developments in the formulation and delivery 
of spray dried vaccines. Hum. Vaccin. Immunother. 13:2364-2378. https://doi.org/10.1080/21645515.2017.1356952.

Li, X., S. G. Thakkar, T. B. Ruwona, R. O. Williams III, and Z. Cui. 2015. A method of lyophilizing vaccines containing aluminum salts into a dry powder without causing particle aggregation or decreasing the immunogenicity following reconstitution. J. Control. Release 204:38-50. https://doi.org/10.1016/j.jconrel.2015.02.035.

Lorenz, I., J. F. Mee, B. Earley, and S. J. More. 2011. Calf health from birth to weaning. I. General aspects of disease prevention. Ir. Vet. J. 64:10. https://doi.org/10.1186/2046-0481-64-10.

Masters, K. 1991. Spray Drying Handbook. 5th ed. Longman Scientific \& Technical. New York, NY.

Merlini, R., G. Gutiérrez, I. Alvarez, J. P. Jaworski, H. Carignano, M. Poli, L. Willems, and K. Trono. 2016. Bovine leukemia virus becomes established in dairy herds before the first lactation. Arch. Virol. 161:3215-3217. https://doi.org/10.1007/s00705-016-2973-x.

Niewold, T. A., A. J. van Dijk, P. L. Geenen, H. Roodink, R. Margry, and J. van der Meulen. 2007. Dietary specific antibodies in spray-dried immune plasma prevent enterotoxigenic Escherichia coli F4 (ETEC) post weaning diarrhoea in piglets. Vet. Microbiol. 124:362-369. https://doi.org/10.1016/j.vetmic.2007.04.034.

Pecora, A., D. A. Malacari, J. F. Ridpath, M. S. Perez Aguirreburualde, G. Combessies, A. C. Odeón, S. A. Romera, M. D. Golemba, and A. Wigdorovitz. 2014. First finding of genetic and antigenic diversity in 1b-BVDV isolates from Argentina. Res. Vet. Sci. 96:204-212. https://doi.org/10.1016/j.rvsc.2013.11.004.

Porta, N. G., I. Alvarez, G. Suarez Archilla, V. Ruiz, A. Abdala, and K. Trono. 2019. Experimental infection of sheep with bovine leukemia virus (BLV): Minimum dose of BLV-FLK cells and cell-free BLV and neutralization activity of natural antibodies. Rev. Argent. Microbiol. 51:316-323. https://doi.org/10.1016/j.ram.2019 .01 .004 .

Pujols, J., and J. Segalés. 2014. Survivability of porcine epidemic diarrhea virus (PEDV) in bovine plasma submitted to spray drying processing and held at different time by temperature storage conditions. Vet. Microbiol. 174:427-432. https://doi.org/10.1016/ j.vetmic.2014.10.021.

Ramezani, V., A. Vatanara, M. Seyedabadi, M. Nabi Meibodi, and H. Fanaei. 2017. Application of cyclodextrins in antibody microparticles: Potentials for antibody protection in spray drying. Drug Dev. Ind. Pharm. 43:1103-1111. https://doi.org/10.1080/03639045 .2017.1293679

Reschke, C., E. Schelling, A. Michel, F. Remy-Wohlfender, and M. Meylan. 2017. Factors Associated with colostrum quality and ef- fects on serum gamma globulin concentrations of calves in Swiss dairy herds. J. Vet. Intern. Med. 31:1563-1571. https://doi.org/10 $.1111 /$ jvim. 14806 .

Romero, C. H., G. B. Cruz, and C. A. Rowe. 1983. Transmission of bovine leukaemia virus in milk. Trop. Anim. Health Prod. 15:215218. https://doi.org/10.1007/BF02242060.

Rubino, M. J., and K. J. Donham. 1984. Inactivation of bovine leukemia virus-infected lymphocytes in milk. Am. J. Vet. Res. 45:15531556.

Ruiz, V., N. G. Porta, M. Lomónaco, K. Trono, and I. Alvarez. 2018. Bovine leukemia virus infection in neonatal calves. risk factors and control measures. Front. Vet. Sci. 5:267. https://doi.org/10.3389/ fvets.2018.00267.

Stott, G. H., D. B. Marx, B. E. Menefee, and G. T. Nightengale. 1979. Colostral immunoglobulin transfer in calves I. Period of absorption. J. Dairy Sci. 62:1632-1638. https://doi.org/10.3168/jds .S0022-0302(79)83472-4.

Trono, K. G., D. M. Pérez-Filgueira, S. Duffy, M. V. Borca, and C. Carrillo. 2001. Seroprevalence of bovine leukemia virus in dairy cattle in Argentina: Comparison of sensitivity and specificity of different detection methods. Vet. Microbiol. 83:235-248. https:// doi.org/10.1016/S0378-1135(01)00420-5.

Van Der Maaten, M. J., and J. M. Miller. 1976. Replication of bovine leukemia virus in monolayer cell cultures. Bibl. Haematol. 43:360362. https://doi.org/10.1159/000399166.

Van Der Maaten, M. J., J. M. Miller, and M. J. Schmerr. 1981. Effect of colostral antibody on bovine leukemia virus infection of neonatal calves. Am. J. Vet. Res. 42:1498-1500.

Vega, C., M. Bok, L. Saif, F. Fernandez, and V. Parreño. 2015. Egg yolk IgY antibodies: A therapeutic intervention against group A rotavirus in calves. Res. Vet. Sci. 103:1-10. https://doi.org/10 $.1016 /$ j.rvsc.2015.09.005

Waldner, C. L., and L. B. Rosengren. 2009. Factors associated with serum immunoglobulin levels in beef calves from Alberta and Saskatchewan and association between passive transfer and health outcomes. Can. Vet. J. 50:275-281.

\section{ORCIDS}

Marina Lomónaco @ https://orcid.org/0000-0003-4647-2858 Irene Álvarez ৫i https://orcid.org/0000-0001-5194-670X 